\title{
Experimental, Statistical Modelling and Molecular Dynamics Simulation Concept of Sapium ellipticum Leaf Extract as Corrosion Inhibitor for Carbon Steel in Acid Environment
}

\author{
Chizoba Sandra Okafor ${ }^{\mathrm{a}}$, Valentine Chikaodili Anadebe ${ }^{\mathrm{b}, \star(\mathbb{D}) \S}$ and Okechukwu Dominic Onukwuli ${ }^{\mathrm{a}}$ \\ ${ }^{a}$ Department of Chemical Engineering, Nnamdi Azikwe University, Awka Anambra State, Nigeria. \\ ${ }^{b}$ Department of Chemical Engineering, Federal University Ndufu Alike, Ebonyi State Nigeria.
}

Received 12 December 2018, revised 17 July 2019, accepted 23 July 2019.

\begin{abstract}
The inhibitive performance of Sapium ellipticum leaf extract as green corrosion inhibitor for carbon steel in varying concentrations in hydrochloric acid has been investigated. To determine the adsorption strength and phenomenon of inhibition, density functional theory was adopted to model the molecular structure of the extract. Also to evaluate the inhibition efficiency weight loss, electrochemical method and statistical modelling was employed. Optimum inhibition efficiency of $89 \%$ was achieved from electrochemical study at conditions of $1.5 \mathrm{~g} \mathrm{~L}^{-1} \mathrm{SE}$ concentration, temperature of $303 \mathrm{~K}$ and $1 \mathrm{M} \mathrm{HCl}$, respectively. The electrochemical study signifies that the phenomenon of inhibition is under mixed control and the inhibition process is in accordance with Langmuir isotherm. Fourier transform infrared spectroscopy (FTIR) of the corrosion particles and surface examination (SEM) confirms the existence of the protective film on the metal surface through the adsorption of extract species.
\end{abstract}

KEYWORDS

Acid corrosion, carbon steel, molecular simulation, statistical modelling, electrochemical study, Sapium ellipticum leaf.

\section{Introduction}

Corrosion of industrial process equipment is a universal challenge that requires sustainable and cheaper solutions. Materials such as plastics, ceramics, metals and alloys are affected by corrosion to varying degrees. It has been documented that processes induced with corrosion of metals and their alloys are predominantly electrochemical. ${ }^{1-2}$ Carbon steel is the most commonly used steel in industries today either in the production of different components of the industrial part or as support for these components. This is relatively due to its low cost and acceptable properties for many industrial applications. Considering the wide use of carbon steel different protective measures are taken into consideration to prolong its life span using more convenient methods. ${ }^{3-4}$ Acid solutions like $\mathrm{HCl}$ and $\mathrm{H}_{2} \mathrm{SO}_{4}$ are usually used in process industries for cleaning, descaling and pickling operations. ${ }^{5}$ Conventional inhibitors have been well documented; however, the quest for achieving clean and green environment suggest the use of plant derived inhibitor as a globally acceptable means of mitigating corrosion. ${ }^{6-7}$ The extract molecules shield the metal from acid attack by forming a coating layer which acts as an impediment between corroding and metal surface. Thus there is need to explore the potentials in the Sapium ellicpticum (SE) leaf extract, considering that it is cost-effective, readily available and eco-friendly.

A series of investigations are available proving the fitness of plant extract as green and novel corrosion inhibitors. Among the various plants inhibitor studied such as ginkgo leaf extract gave efficiency of $92.5 \%$ for mild steel in $1 \mathrm{M} \mathrm{HCl}$ at inhibitor concentration of $200 \mathrm{mg} \mathrm{L}^{-1}, 8$ Rosmarinus officinalis extract gave efficiency of $93.26 \%$ for low carbon steel in $1 \mathrm{M} \mathrm{HCl}$ at inhibitor concentration $3 \%,{ }^{9}$ bitter kola leaf extract gave efficiency of $90 \%$ for mild steel in $1.2 \mathrm{M} \mathrm{HCl}$ at inhibitor concentration of $0.9 \mathrm{~g} \mathrm{~L}^{-1}$,

* To whom correspondence should be addressed.

E-mail: anadebechika@gmail.com / anadebe.valentine@ funai.edu.ng
Mitracarpus hirtus extract gave efficiency of $89 \%$ for mild steel in $1 \mathrm{M} \mathrm{HCl}$ at inhibitor concentration of $0.6 \mathrm{~g} \mathrm{~L}^{-1},{ }^{11}$ Aegle marmelos extract gave efficiency of $83 \%$ for mild steel in $0.5 \mathrm{M} \mathrm{H}_{2} \mathrm{SO}_{4}$ at inhibitor concentration of $500 \mathrm{mg} \mathrm{L}^{-1}$. $^{12}$

Bio-extracts are known to contain minute chemical constituents; in view of this it is cumbersome to isolate a definite constituent behind the inhibition process. The phenomenon of analyzing the assistance of different constituents to the overall inhibiting effect of biomass is usually complicated, thus the density functional theory (DFT) has been useful in this aspect.

Current technology in DFT-based quantum chemistry has made this technique readily available to corrosion engineers for detailed theoretical study of metal degradation and control measures.

Response surface methodology (RSM) is a useful statistical tool, which has been adopted in research for optimizing various processes in which a response of interest is influenced by many factors. The aim is to optimize the response while minimizing the number of experimental runs required to obtain accurate and statistical data analysis.

Sapium ellipticum belongs to the family Euphorbiaceae and is usually referred as jumping seed tree. It has contributed so much in the local treatment of series of diseases including diabetes. ${ }^{13}$ It is cultivated in the eastern and tropical Africa. The antimicrobial and antioxidant activities of SE leaf were attributed to the nature of the phytochemical constituents in the plant and to the best of our knowledge, investigation on the use of SE leaf extract as green corrosion inhibitor for carbon steel in aggressive and alkaline environment is scarce, thus the aim of this area of investigation is, first to evaluate the performance of SE as green sustainable inhibitor in acid environment, secondly to theoretically isolate and test the most active constituents of SE leaf extract to the overall inhibition process using DFT, thirdly to evaluate the optimum inhibition efficiency using response surface methodology. 


\section{Experimental}

\subsection{Preparation of Plant Extract}

Fresh Sapium ellipticum leaf sample were sourced from Sapium ellipticum orchard at Uli in Anambra State of Nigeria. $1.0 \mathrm{~kg}$ of leaves was collected from matured plants. The sample leaves were conveyed in a plastic bag to the laboratory. At the start of the experiment the samples were washed under running water and sun-dried for 4 days in a control environment. It was thereafter ground into powder and stored in sample bottle for extraction process. The extraction process was carried in batches. $30 \mathrm{~g}$ of the SE leaf powder were weighed and immersed in $1000 \mathrm{~mL}$ of ethanol for $48 \mathrm{~h}$. Separation procedure applied in the previous work was adopted to obtain the plant extract. ${ }^{14}$ The $\mathrm{HCl}$ (JHD) and ethanol (JHD) used for the practical were of high grade.

\subsection{Metals Preparation}

Corrosion studies were performed on carbon steel of compositions (wt. \%) 0.3 C, 0.6 Mn, 0.04 P, 0.03 Mo, 2.2 Si, 0.15 Ni, 0.5 Cu and $96 \%$ Fe. Prior to corrosion process, the carbon steel was mechanically cut. The surface of each coupon were then polished using 220, 800 and 1200 emery papers to obtain a smooth area. The coupons were further degreased with acetone rinsed with distilled water to remove debris and dry in warm air according to previous work done. ${ }^{15}$

\subsection{Characterization of Sapium ellipticum Leaf Extract}

Titrimetric method was used to identify the phytochemicals of the extract. Prior to the experiment, FTIR analysis was carried out on the crude sample Sapium ellipticum (SE) to identify the active functional groups. Metal coupons were further introduced in the inhibited medium. After the corrosion investigation, corrosion particles were scooped, mixed with KBR (potassium bromide) and subjected to infrared spectroscopy using (SHIMADZU Model IR affinity-1, S/N A213747013651) to identify the functional group in the corrosion products.

\subsection{Weight Loss Method}

Weight loss method was performed at temperatures of $303 \mathrm{~K}$, $318 \mathrm{~K}$ and $333 \mathrm{~K}$, respectively. As previously expressed ${ }^{10,16}$ the variation in the initial and final weight was studied for unprotected and protected test solution. At the end of corrosion study the coupons were removed, dipped in acetone, cleaned and finally re-weighed. The experimental data were recorded and evaluated using the Equations (1), (2), (3) and (4) as adopted from literature. ${ }^{17}$

$$
\begin{aligned}
& \Delta \mathrm{w}=\mathrm{w}_{\mathrm{i}}-\mathrm{w}_{\mathrm{f}} \\
& \mathrm{CR}=\frac{\mathrm{w}_{\mathrm{bl}_{1}}-\mathrm{w}_{\mathrm{inh}}}{\text { Area }(\mathrm{m} 2) \times \mathrm{t}(\text { time }) \text { day }} \\
& \mathrm{IE} \%=\frac{\mathrm{w}_{\mathrm{bl}}-\mathrm{w}_{\text {inh }}}{\mathrm{w}_{\mathrm{bl}}} \times 100 \\
& \theta=\frac{\mathrm{w}_{\mathrm{bl}}-\mathrm{w}_{\text {inh }}}{\mathrm{w}_{\mathrm{bl}}}
\end{aligned}
$$

where $\Delta \mathrm{w}$ represents average weight loss of carbon steel, $\mathrm{w}_{\mathrm{i}}$ and $\mathrm{w}_{\mathrm{f}}$ are the initial and final weight of the coupons. $\mathrm{w}_{\mathrm{bl}}$ and $\mathrm{w}_{\text {inh }}$ are the weight loss values obtained in the unprotected and protected medium. A denotes area of carbon steel and $t$, time of study, CR is the corrosion rate, IE\% is the inhibition efficiency and $\theta$ is the total surface coverage. The relevance of calculating IE\% via Equations (3) and (5) is that in corrosion study different techniques such as weight loss, thermometric, electrochemical study are employed to evaluate corrosion rate CR and inhibition efficiency IE\% as such it has different equations for proper evaluation. Equation (3) is mainly used in traditional weight loss method while Equation (5) is usually used in advanced electrochemical techniques.

\subsection{Electrochemical Test}

Thorough electrochemical analysis was performed with the aid of a potentiostat/galvanostat 263 electrochemical system workstation. Within the context of this study a graphite bar and a calomel electrode (CE) were employed as a reference electrode. The experiment was performed in aerated and unstirred solution at the end of $1800 \mathrm{~s}$ of immersion at $303 \mathrm{~K}$. This makes the solution to stabilize. Carbon steel specimen of $1 \mathrm{~cm}^{2}$ dimension was used as working electrode. Experiment was performed considering $\pm 250 \mathrm{mV} \mathrm{VS} \mathrm{E}_{\text {corr }}$ and further examine sequentially at speed of $0.333 \mathrm{mV} / \mathrm{s}$. Tests to investigate the influence of low and high concentration of SE extract on the electrochemical behaviour of carbon steel in $1 \mathrm{MHCl}$ were analyzed using inhibitor concentrations of $0.3 \mathrm{~g} \mathrm{~L}^{-1}$ and $1.5 \mathrm{~g} \mathrm{~L}^{-1}$, respectively. Each test was run in triplicate to evaluate the reproducibility of average values obtained. This was calculated using Equation (5).

$$
\mathrm{IE} \%=\frac{\mathrm{i}_{\text {corr (bl) }}-\mathrm{i}_{\text {corr(inh) }}}{\mathrm{i}_{\text {corr(bl) }}} \times 100
$$

where (bl) and (inh) are the current density values in the absence and presence of inhibitor.

\subsection{Molecular Dynamics Simulation Concept}

The quantum chemistry analysis was carried using the DFT electronic diagram programs Forcite and $\mathrm{DMol}^{3}$ as embedded in the Materials Studio 4.0 software. The electronic parameters for the simulation include unrestricted spin polarization using DND basis set and perdew-Wang (PW) local correlation density functional. The Fe slab for the simulations was cleaved along the (110) plane. The calculations were performed in a $12 \times 10$ super cell using a Compass force field (condensed phase optimized molecular potential simulation studies) and the Smart algorithm with NVE (micro canonical) ensemble, a time step of $1 \mathrm{fs}$ and simulation time of $5 \mathrm{ps}$. The temperature was fixed at $303 \mathrm{~K}$. The system was quenched automatically at intervals of 250 steps.

\subsection{Activation and Heat of Adsorption}

Considering corrosion rates of the mild steel at $\mathrm{T}_{1}$ and $\mathrm{T}_{2}$ as $C_{R_{1}}$ and $C_{R_{2}}$, Equation (6) was used to evaluate and predict the activation energy. The heat of adsorption $\mathrm{Q}_{\text {ads }}\left(\mathrm{KJ} \mathrm{mol}^{-1}\right)$ was calculated using Equation (7).

$$
\begin{aligned}
& \ln \left(C_{R_{2}} / C_{R_{1}}=\left(\frac{E_{a}}{2.303 R}\right)\left(\frac{1}{T_{1}}-\frac{1}{T_{2}}\right)\right. \\
& Q_{\text {ads }}=2.303 R\left[\log \left(\frac{\theta_{2}}{1-\theta_{2}}\right)-\log \left(\frac{\theta_{1}}{1-\theta_{1}}\right)\right] \times \frac{\mathrm{T}_{2}-\mathrm{T}_{1}}{\mathrm{~T}_{2}-\mathrm{T}_{1}}
\end{aligned}
$$

where $\mathrm{E}_{\mathrm{a}}$ is the activation energy, $\mathrm{R}$ denotes gas constant, $\theta_{1}$ and $\theta_{2}$ represent degree of surface coverage at temperature $T_{1}$ and $T_{2}$. $\theta_{1}$ and $\theta_{2}$ were evaluated using Equation (4) of section 2.4

Then the free energy of adsorption $\left(\delta \mathrm{G}_{\mathrm{ads}}\right)$ was evaluated using Equation (8).

$$
\Delta \mathrm{G}_{\mathrm{ads}}=-2.303 \mathrm{RT} \log (55 \mathrm{~K})
$$

\subsection{Scanning Electron Microscopy}

Morphological analysis of the corroded coupons were carried out at Chemical Engineering Department Ahmadu Bello University, Zaria using the scanning electron microscope (SEM of model no. MVE016477830), Netherlands. 


\section{Results and Discussions}

\subsection{Phytochemical Analysis}

Phytochemical screeening was carried out on Sapium ellipticum leaf extract (SE) it was observed that the extract is rich in flavonoids $(+)$, phenolics $(+)$, alkaloids $(+)$, saponins $(-)$, tannins $(+)$ which made it to be useful in traditional medicine and these bioactive constituents are centre for adsorption process.

\subsection{IR Spectral Analysis of Sapium ellipiticum Leaf Extract} and Corrosion Particles

The active functional groups in SE molecules accountable for surface attachment and obstruction of corrosion of carbon steel was determined through FTIR analysis and compared with data base spectrum. The FTIR spectrum of $1 \mathrm{M} \mathrm{HCl} /$ SE extract prior and after corrosion study are shown in Fig. 1 and Fig. 2. The SE spectrum prior to corrosion investigation revealed the variation

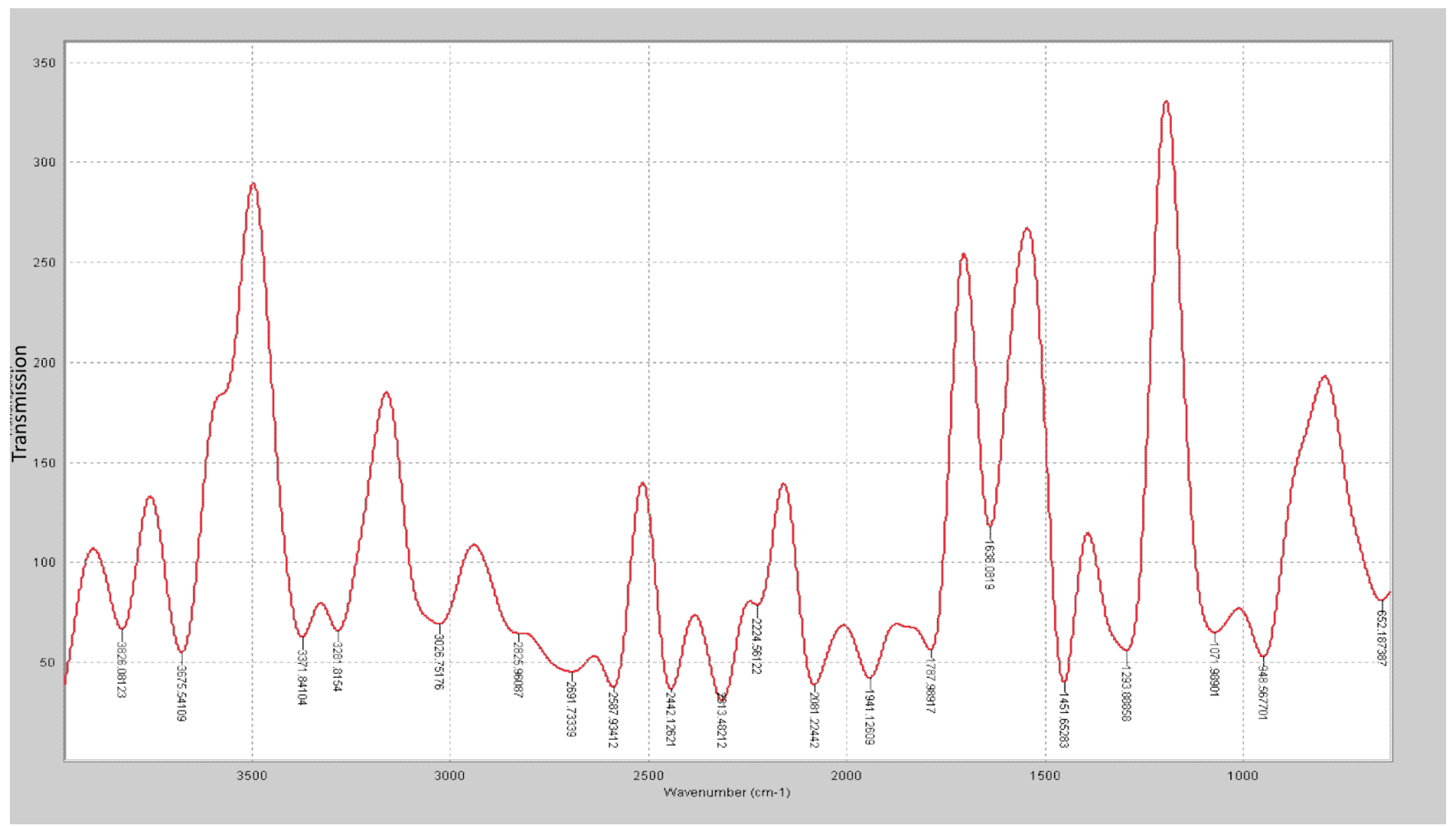

Figure 1 IR Spectral of Sapium ellipiticum leaf extract.

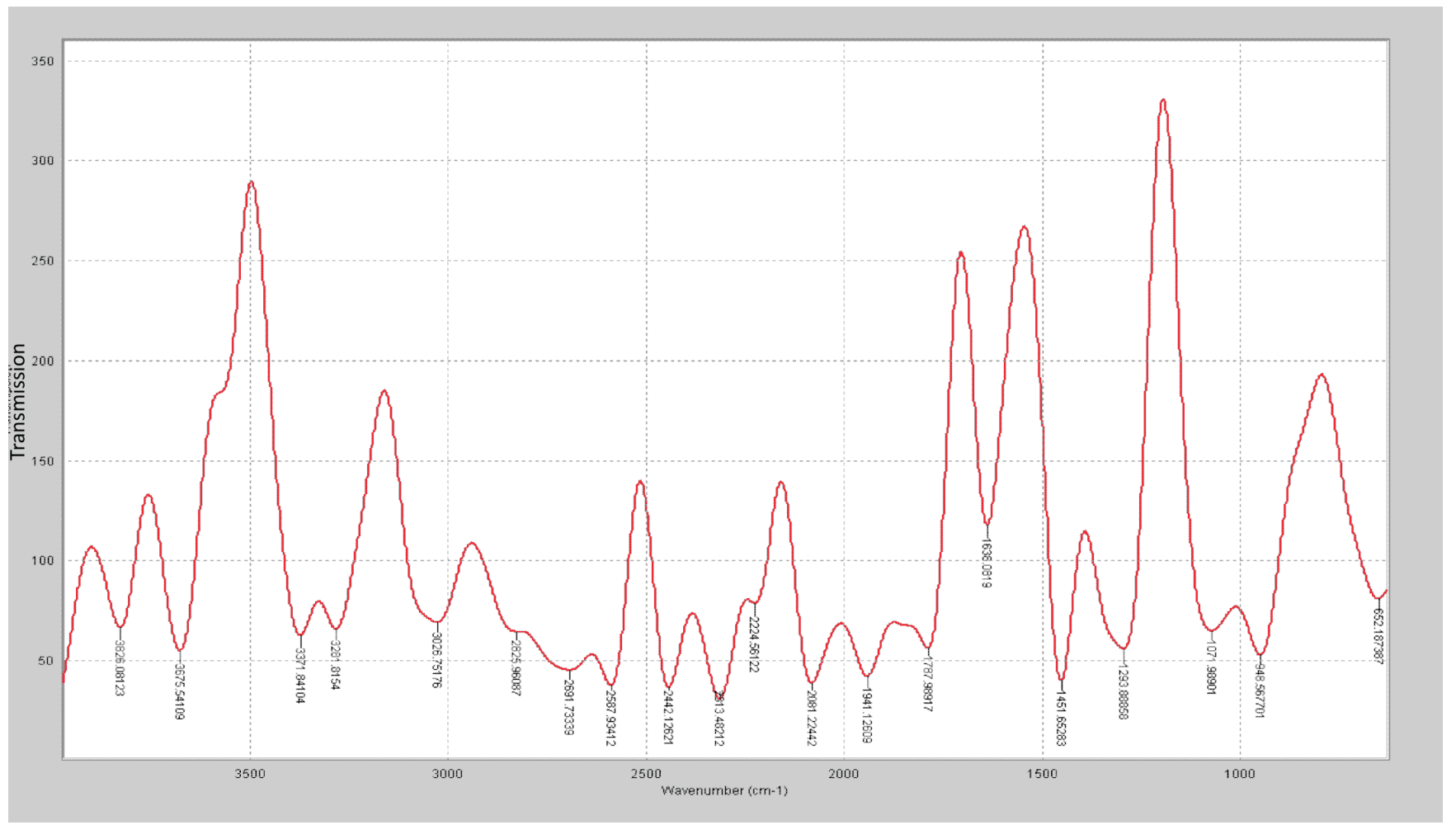

Figure 2 IR Spectral of carbon steel in $1 \mathrm{M} \mathrm{HCl}$ with Sapium ellipiticum leaf extract. 
of peaks at wave number of $3675.08 \mathrm{~cm}^{-1}, 3281.81 \mathrm{~cm}^{-1}$, $3026.75 \mathrm{~cm}^{-1}, 2691.73 \mathrm{~cm}^{-1}, 2224.56 \mathrm{~cm}^{-1}, 1941.12 \mathrm{~cm}^{-1}$, $1638.08 \mathrm{~cm}^{-1}, 1451.65 \mathrm{~cm}^{-1}, 1071.98 \mathrm{~cm}^{-1}, 948.56 \mathrm{~cm}^{-1}$ and $652.18 \mathrm{~cm}^{-1}$. By comparing the values with the standard FTIR data base, functional groups of $\mathrm{O}-\mathrm{H}$ stretch (alcohol and phenol), $\mathrm{N}-\mathrm{H}$ stretch of primary amine and amides, C-H stretch of Aldehydes, $\mathrm{C} \equiv \mathrm{N}$ of unsaturated nitrogen, $\mathrm{N}-\mathrm{H}$ deformation of carbonyl group, $\mathrm{C}=\mathrm{C}$ stretch of aromatics, $\mathrm{C}-\mathrm{O}$ stretch of ethers and C-Br stretch of alkyl halides were isolated in the molecular structure of SE which was further tested as corrosion inhibitor using density functional theory. The FTIR analysis of the corrosion particles revealed that most FTIR peaks have deviated from their original position, ${ }^{18}$ the deviation and shifting mechanism in the wave number of absorption signifies the attachment of $\mathrm{O}-\mathrm{H}$, $\mathrm{C}-\mathrm{O}$ and $\mathrm{C}=\mathrm{C}$ molecules at those peaks and this phenomenon led to the formation of a dense protective film layer on the steel surface.

\subsection{Mass Loss Method}

Mass loss technique is globally adopted in scientific laboratory and engineering industries. The major advantage of the technique is that tested inhibitor dissolves in water, it is simple and convenient to ascertain corrosion conditions and few dose of inhibitor is desired for experiments. Table 1 depicts the dissolution rate and inhibition efficiency of carbon steel by mass loss evaluation at different concentrations of $\mathrm{SE}$ in $\mathrm{HCl}$ operating under $303 \mathrm{~K}, 318 \mathrm{~K}$ and $333 \mathrm{~K}$, respectively. It is evident that the dissolution rates are reduced in the protected medium of SE compared to unprotected medium for carbon steel in $1 \mathrm{M} \mathrm{HCl}$. The efficacy of SE can be ascribed to the attachment of SE active molecules on the surface of carbon steel. The corrosion level of carbon steel decreases, whereas the inhibition efficiency increases with an increment in the thickness of SE molecules at all temperature. Increased surface coverage with concentration implies that large SE molecules are adsorbed on carbon steel at elevated concentrations thereby enhancing the manifestation of

Table 1 Gravimetric results of carbon steel specimen in $1 \mathrm{M} \mathrm{HCl}$ and $2 \mathrm{M}$ $\mathrm{HCl}$ with SE extract.

\begin{tabular}{lccccccc}
\hline \multirow{2}{*}{$\begin{array}{l}\text { Acid conc.: } \\
\text { Temperature: }\end{array}$} & \multicolumn{3}{c}{$1 \mathrm{M} \mathrm{HCl}$} & & \multicolumn{3}{c}{$2 \mathrm{M} \mathrm{HCl}$} \\
\cline { 2 - 4 } \cline { 6 - 8 } & $303 \mathrm{~K}$ & $318 \mathrm{~K}$ & $333 \mathrm{~K}$ & & $303 \mathrm{~K}$ & $318 \mathrm{~K}$ & $333 \mathrm{~K}$ \\
\hline $0.3 \mathrm{~g} \mathrm{~L}^{-1} / \mathrm{SE}$ & 65.37 & 59.16 & 41.24 & 55.33 & 52.54 & 48.93 \\
$0.6 \mathrm{~g} \mathrm{~L}^{-1} / \mathrm{SE}$ & 72.19 & 65.16 & 47.24 & & 61.33 & 59.36 & 56.44 \\
$1.2 \mathrm{~g} \mathrm{~L}^{-1} / \mathrm{SE}$ & 81.18 & 72.83 & 54.91 & & 69.00 & 68.35 & 66.90 \\
$1.5 \mathrm{~g} \mathrm{~L}^{-1} / \mathrm{SE}$ & 87.02 & 81.16 & 63.24 & & 77.33 & 74.05 & 69.52 \\
\hline
\end{tabular}

the protective film. ${ }^{19}$ Further observation revealed that inhibition efficiency decreases with enhancing temperature both in protected and unprotected medium reason being that the attached film layer is being dispersed or agitated at elevated temperature.

\subsection{Adsorption / Thermodynamics study}

The phenomenon through which SE extract attach on the carbon steel obstructing the dissolution of its surface can further be discussed through adsorption isotherms. The phenomenon of inhibition is due to the mutual interactions between the steel interface and the $\pi$ electrons within the heteroatoms of SE, molecular adsorption from liquid phase is cumbersome to understand and rely on the composition of the interface area between the steel and acid media. It also relies on the quantity, existence and characteristics of surface oxide groups and functional groups formed through dissolution taking place during activation process. A series of adsorption models have been well studied and adopted to evaluate experimental data. In this study Langmuir adsorption isotherm was proposed as shown in Fig. $3^{20-22}$

$$
\frac{\mathrm{C}}{\theta}=\frac{1}{\mathrm{~K}_{\mathrm{ads}}}+\mathrm{C}
$$

$\mathrm{C}$ represent concentration of inhibitor, $\mathrm{K}_{\mathrm{ads}}$ denotes adsorption equilibrium. As revealed by the plot of $\mathrm{C} / \theta$ versus $\mathrm{C}$ yields a linear graph where the slope is near unity due to the surface attachment of each SE molecule on individual active site on the steel surface. It could be clearly seen that the attachment of SE inhibitor onto the surface of carbon steel strongly conform with the Langmuir isotherm with a high correlation coefficient $R^{2}(0.9905)$ and slope of about unity (1.4151). The parameters for Langmuir isotherms are presented in Table 2. Also in Table 3 the results show that the activation energy in the absence of $\mathrm{SE}$ in $\mathrm{HCl}$ (unprotected solution) was found to be lower than the corresponding activation energies in the presence of different concentration of SE molecules. Further observation revealed that the activation energies increase as the concentration of SE molecules increases due to the spontaneous accumulation of SE molecules on steel surface which led to a considerable surface coverage and the film layer is seen to be higher than the destruction of the steel surface. ${ }^{10}$

\subsection{Electrochemical Impedance Spectroscopy}

Inhibition efficiency of Sapium ellipticum (SE) leaf extract on carbon steel (CS) degradation in acid medium $(1 \mathrm{M} \mathrm{HCl})$ is the subject of this investigation, EIS was adopted and performed on CS in unprotected and protected medium with $0.3 \mathrm{~g} \mathrm{~L}^{-1}$

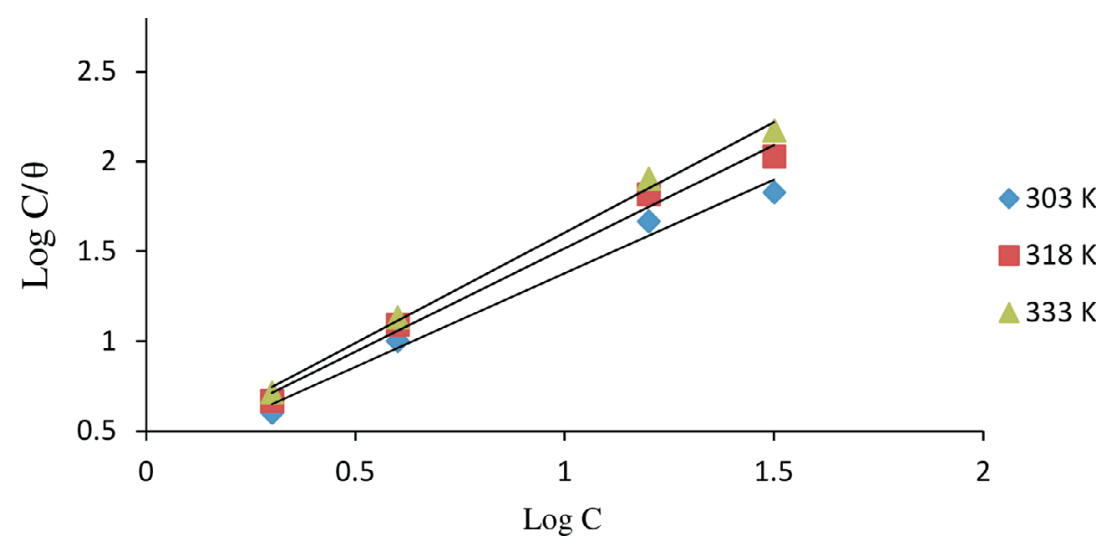

Figure 3 Plot of $\log \mathrm{C} / \theta$ vs. $\log \mathrm{C}$ (concentration of SE) on carbon steel in $1 \mathrm{M} \mathrm{HCl}$. 
Table 2 Langmuir adsorption parameter for carbon steel in $1 \mathrm{M} \mathrm{HCl}$ with SE extract.

\begin{tabular}{lccccc}
\hline Temp/K & Log K & $\mathrm{K}$ & Slope & $\Delta \mathrm{G} / \mathrm{KJ} \mathrm{mol}^{-1}$ & $\mathrm{R}^{2}$ \\
\hline 303 & 0.3494 & 2.8620 & 1.3649 & -12.7691 & 0.9820 \\
318 & 0.3732 & 2.6795 & 1.4058 & -13.2270 & 0.9919 \\
333 & 0.4123 & 2.4254 & 1.4747 & -13.5750 & 0.9975 \\
Mean & 0.3783 & 2.6434 & 1.4151 & -13.1904 & 0.9905 \\
\hline
\end{tabular}

Table 3 Activation and heat adsorption studies.

\begin{tabular}{lcc}
\hline Conc./g L & Activation energy $(E a)$ & Heat of adsorption $\left(\mathrm{Q}_{\text {ads }}\right)$ \\
\hline Blank & 30.40 & \\
0.3 & 34.45 & -7.46 \\
0.6 & 34.03 & -5.51 \\
1.2 & 33.48 & -2.38 \\
1.5 & 37.19 & -9.24 \\
\hline
\end{tabular}

and $1.5 \mathrm{~g} \mathrm{~L}^{-1}$ concentration of SE. The Nyqiust spectrum is displayed in Fig. 4. The circumference of the nyquist semicircle is connected to charge transfer process of the steel degradation. ${ }^{23}$ The middle of these depressed semicircles was gentle shifted below the real axis. It is also vital to state that all impedance spectrum have a depressed semicircle which may be ascribed to the influence of frequency dispersion because of the dark flakes, coarseness and texture of the carbon steel surface. ${ }^{24-26}$ Addition of SE extended the magnitude of the impedance spectrum which indicates obstruction of corrosion process due to the organic compounds in SE which formed a protective film on the steel surface. Also capacitive loop increased by enhancing the thickness of SE extracts due to the bulky attachment of SE molecules on the steel surface, implying that the film layer gentle spread on steel surface by spontaneous accumulation which results to strong formation of the coating film. On the contrary, as the temperature is enhanced the magnitude of the capacitive loop reduces; this could be ascribed to the nature of corrosive medium and $\mathrm{pH}$ of the studied environment. However, the circumference of the spectrum was adequately enhanced with the addition of SE extract with respect to the unprotected medium which generally describes the unique protection of SE extracts within the studied range.

Furthermore, the values of the impedance parameters were input to the circuit model which was employed to model the metal interface. Within the context of this study CPE is used to substitute a capacitor in order to investigate the deviation from ideal dielectric behaviour due to the coarseness and texture of the electrode surface. The equation of the CPE impedance is as follows. ${ }^{27-28}$

$$
Z_{\mathrm{CPE}}=\frac{1}{\mathrm{Y}_{0}(j w)^{\mathrm{n}}}
$$

where $Y_{0}$ signifies the admittance electrochemical system, $j$ denotes the imaginary number, is regarded as angular frequency, $\mathrm{n}$ is the shifting parameter explaining the heterogeneity of the steel surface and $R_{s}$ indicates the solution resistance. The obtain results of $C f$ and $C_{\mathrm{dl}}$ are evaluated with Equation (11) by $\omega, \mathrm{n}$ and $\mathrm{Y}_{0}{ }^{29}$

$$
\mathrm{C}=\mathrm{Y}_{0}(\omega)^{\mathrm{n}-1}=\mathrm{Y}_{0}\left(2 \pi \mathrm{f}_{\text {zim-max }}\right)^{\mathrm{n}-1}
$$

$\mathrm{F}_{\text {zim-max }}$ is frequency connected to the optimum imaginary impedance.

\subsection{Polarization Measurement}

Figure 5 signifies the polarization curve of the carbon steel in unprotected and protected medium. Table 5 lists the necessary electrochemical variables which includes corrosion current density $\left(\mathrm{I}_{\text {corr }}\right)$, corrosion potential $\left(\mathrm{E}_{\text {corr }}\right)$, Tafel slope of anodic and cathodic $(\beta \mathrm{a} \beta \mathrm{c})$ with inhibition efficiency (IE\%). The data presented therein signifies that in $\mathrm{HCl}$ environment the $\mathrm{I}_{\text {corr }}$ decreases in the protected medium compared to the unprotected medium and the phenomenon continues with an increment in the thickness of the SE molecules. Thorough scrutiny of the curve in Fig. 5 reveals that the SE influenced both the cathodic and anodic reaction and hence the addition of SE reduced the metal dissolution and rate of hydrogen evolution reaction on carbon steel surface.

It is clear that addition of $\mathrm{SE}$ in $1 \mathrm{M} \mathrm{HCl}$, the $\mathrm{E}_{\text {corr }}$ shift towards the novel direction and SE acts as a very effective anti-corrosion agent for surface modification of carbon steel $1 \mathrm{M} \mathrm{HCl}$. The inhibition efficiency increased with an increase in concentration of SE molecules. Further observation, the concentration of SE extract employed for the study was very effective even at a minimal concentration and signifies the great deal of activeness

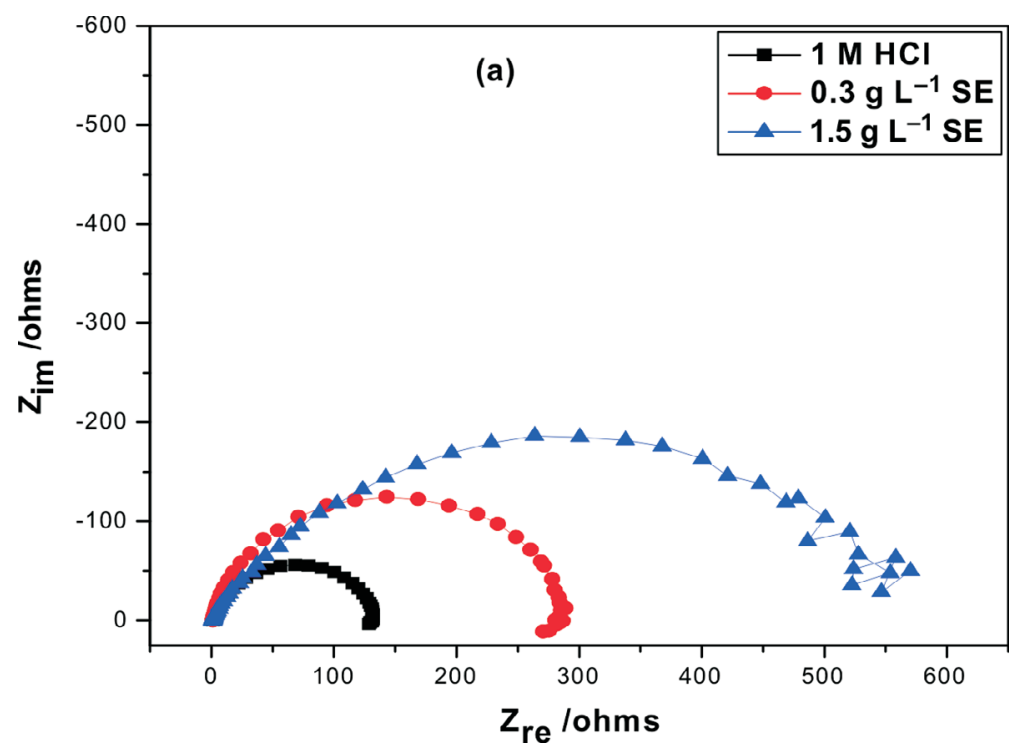

Figure 4 Impedance spectrum of carbon steel with $0.3 \mathrm{~g} \mathrm{~L}^{-1}$ and $1.5 \mathrm{~g} \mathrm{~L}^{-1} \mathrm{SE}$ in $1 \mathrm{M} \mathrm{HCl}$. 


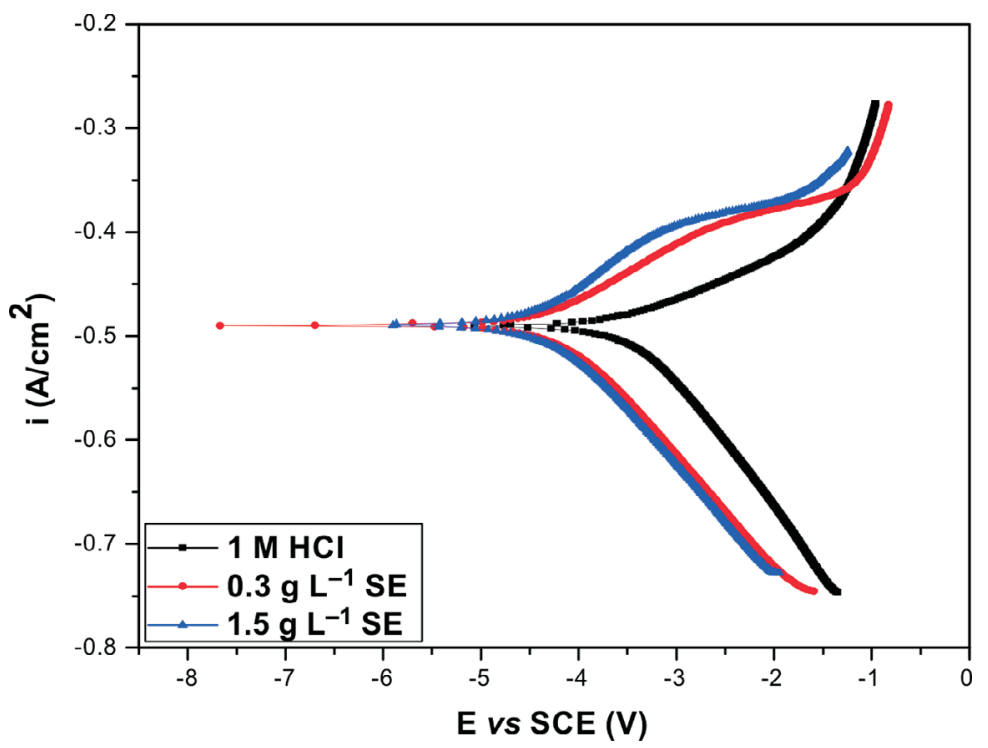

Figure 5 Polarization curves of carbon steel with $0.3 \mathrm{~g} \mathrm{~L}^{-1}$ and $1.5 \mathrm{~g} \mathrm{~L}^{-1} \mathrm{SE}$ in $1 \mathrm{M} \mathrm{HCl}$.

Table 4 Impedance data for carbon steel in $1 \mathrm{M} \mathrm{HCl}$.

\begin{tabular}{lccccc}
\hline System & $\mathrm{R}_{\mathrm{s}} / \Omega \mathrm{cm}^{2}$ & $\mathrm{R}_{\mathrm{ct}} / \Theta \mathrm{cm}^{2}$ & $\mathrm{n}$ & $\mathrm{C}_{\mathrm{dl}} / \mathrm{F} \mathrm{cm}^{2}$ & $\mathrm{IE} / \%$ \\
\hline $1 \mathrm{M} \mathrm{HCl}$ & 1.565 & 122.5 & 0.89 & $6.908 \mathrm{E}-5$ & \\
$1 \mathrm{M} \mathrm{HCl}+$ & 1.710 & 293.6 & 0.89 & $6.982 \mathrm{E}-5$ & 58.3 \\
$0.3 \mathrm{~g} \mathrm{~L} \mathrm{SE}$ & & & & & \\
$1 \mathrm{M} \mathrm{HCl}+$ & 2.330 & 548.3 & 0.89 & $6.033 \mathrm{E}-5$ & 87.7 \\
\begin{tabular}{l}
$1.5 \mathrm{~g} \mathrm{~L} \mathrm{SE}$ \\
\hline
\end{tabular} & & & & & \\
\hline
\end{tabular}

of SE to carbon steel surface. The effectiveness was probably due to the conjugate structures of the heterocyclic compounds existing in $\mathrm{SE}$ extracts. Considering the difference in $\mathrm{E}_{\text {corr }}$ between the unprotected and the protected medium SE is regarded as a mixed-type inhibitor. ${ }^{30-33}$

In conclusion, the trend of inhibition in Table 5 is due to intermolecular relationship between the protonated SE molecules and valence electrons on the Fe surface.

\subsection{Molecular Dynamics Simulation Concept}

Quantum chemical study, gives in depth understanding about molecular adsorption and corrosion inhibition phenomenon, the surface interactions of corrosion inhibitors and metals rely on the composition and characteristics of the studied inhibitor. These compositions are connected with the existence of a definite group in the heterocyclic compounds such as $\pi$-bonds, electron density and aromatics. It has been documented that such molecules with these functional groups greatly tends to be identified as corrosion inhibitor. ${ }^{34}$ Highest occupied molecular orbital HOMO and lowest unoccupied molecular orbital LUMO display a major character in the activeness of SE extract with the metal surface. $\mathrm{E}_{\text {Номо }}$ denotes the ability of a species to give electrons, implying that the greater is $\mathrm{E}_{\text {номо }}$ values the better chance of achieving excellent protection efficiency. ${ }^{35}$ While $\mathrm{E}_{\mathrm{LUMO}}$ corre- sponds to the ability of a species to receive electrons, ${ }^{36-38}$ thus a good corrosion inhibitor should be scrutinized by low $\mathrm{E}_{\text {LUMO }}$ values. ${ }^{39}$ The variation between the $\mathrm{E}_{\text {номо }}$ and $\mathrm{E}_{\text {Luмо }}$ describe the energy gap of a molecule. Also molecules with low energy gap $(\delta$-CAPE) values may give high protection efficiency due to its chemical reactivity. ${ }^{40}$

In order to get the mechanistic interpretation of the adsorption sites, molecular dynamics simulation were carried to model the active structure of SE to the overall inhibition efficiency. The optimized structure of amentoflavone and metal were employed for the simulation. The geometry of the bottom layers of the Fe (110) slab was constrained; hence the energy of the forces between them remained steady throughout the simulation and was excluded from the calculation since they will not affect the overall movement of the adsorbed molecule. The studied molecule (amentoflavone) is a well-known bioflavonoid occurring in many natural products. It has been documented to have some vital bioactivities. ${ }^{41}$ It is necessary to explain here the nature and type of functional groups existing in SE molecules. In this present investigation, the $\mathrm{HOMO}$ area is greatly distributed within the heteroatoms, while the LUMO area is adequately distributed more in the hydroxyl group due to the tough intermolecular relationship between the protonated SE molecules and valence electrons on the Fe surface through electrostatic mechanism. Also the carbon-carbon bonds are easily hydrogenated. The data listed in Table 6 prove that SE extract has high values of $\mathrm{E}_{\text {номо }}$ and low $\mathrm{E}_{\text {Luм⿰. }}$ As revealed in Fig. 6 when the attachment of the active compound of SE attain equilibrium all the atoms were arranged in a parallel direction on the Fe surface, this position increased the degree of surface coverage, however this does not mean that other active components do not participate in the inhibition phenomenon. It is good to note in SE, where there are various components, the overall inhibition process is due to the synergistic attachment of the various active

Table 5 Parameter from Tafel polarization measurements.

\begin{tabular}{lcccccc}
\hline System & $\begin{array}{c}\mathrm{E}_{\text {corr }} \\
(\mathrm{mV} \text { vs. SCE })\end{array}$ & $\begin{array}{c}\mathrm{I}_{\text {corr }} \\
(\mathrm{mV} \text { vs. SCE })\end{array}$ & $\begin{array}{c}\beta \mathrm{c} \\
/ \mathrm{mV} \mathrm{dec}^{-1}\end{array}$ & $\begin{array}{c}\beta \mathrm{a} \\
/ \mathrm{mV} \mathrm{dec}^{-1}\end{array}$ & $\begin{array}{c}\Theta \\
\theta\end{array}$ \\
\hline $1 \mathrm{M} \mathrm{HCl}$ & -496.2 & 186.2 & 120.4 & 99.5 & - & 50.2 \\
$1 \mathrm{M} \mathrm{HCl}+0.3 \mathrm{~g} \mathrm{~L}^{-1} \mathrm{SE}$ & -490.3 & 84.6 & 109.3 & 74.4 & 0.502 & 502 \\
$1 \mathrm{M} \mathrm{HCl}+1.5 \mathrm{~g} \mathrm{~L}^{-1} \mathrm{SE}$ & -497.9 & 15.7 & 100.2 & 71.2 & 0.892 & 89.2 \\
\hline
\end{tabular}




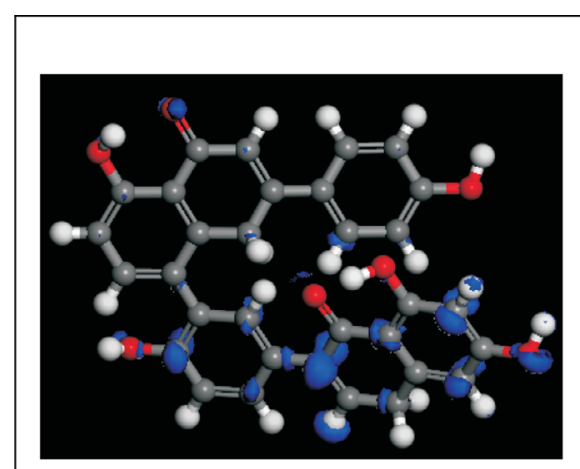

(a) Electrophilic

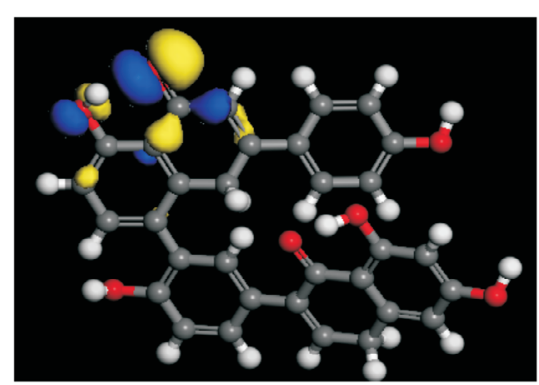

(d) $\mathrm{HOMO}$

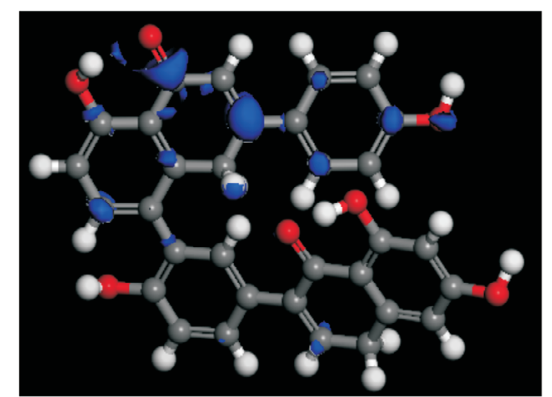

(b) Nucleophilic

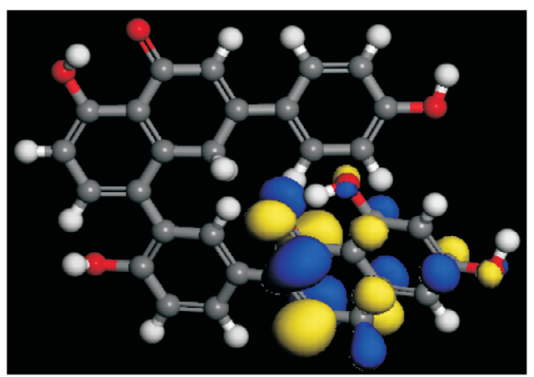

(e) LUMO

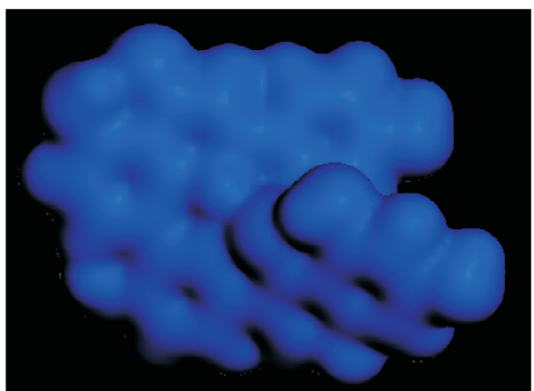

(c) Electron Density

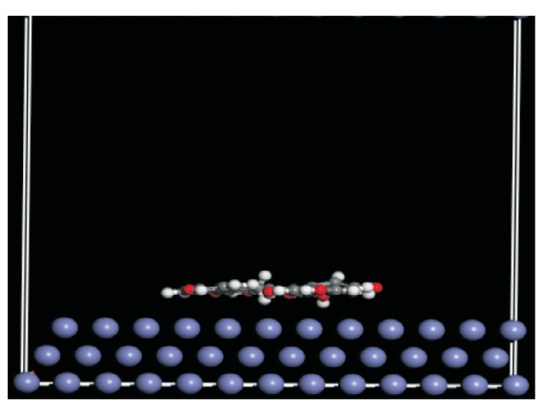

(f) MD - simulation

Figure 6 Electronic properties of amentoflavone: (a) electrophilic F-, (b) nucleophilic F+, (c) electron density , (d) HOMO, (e) LUMO, (f) snapshot for amentoflavone from molecular dynamics simulation. Atom legend: white $=\mathrm{H}$; gray $=\mathrm{C}$; red $=\mathrm{O}$; blue $=\mathrm{N}$. The blue and yellow iso-surfaces depict the electron density difference: the blue regions show electron accumulation while the yellow regions show electron loss.

Table 6 Computed values of quantum chemical parameter assessed at DFT.

\begin{tabular}{lccccc}
\hline Inhibitor & $\begin{array}{c}\mathrm{E}_{\mathrm{HOMO}} \\
\mathrm{eV}\end{array}$ & $\begin{array}{c}\mathrm{E}_{\mathrm{Lumo}} \\
\mathrm{eVV}\end{array}$ & Energy gap & Mol. & $\begin{array}{c}\text { Mass binding } \\
\text { energy/kcal }\end{array}$ \\
\hline Amentoflavone & -4.531 & -3.894 & 0.637 & 538 & -154.0 \\
\hline
\end{tabular}

molecules of SE and the charge transfer process is saturated across the active molecules. In order to quantify the interaction between the molecules and the Fe surface, the adsorption energy $\left(E_{\text {ads }}\right)$ of the system was calculated using Equation (12).

$$
\mathrm{E}_{\mathrm{ads}}=\mathrm{E}_{\text {total }}-\left(\mathrm{E}_{\mathrm{SE}}+\mathrm{E}_{\mathrm{Fe}}\right)
$$

$\mathrm{E}_{\text {Total }}$ is regarded as the entire energy of the simulation area involving SE molecules and Fe surface, $\mathrm{E}_{\mathrm{SE}}, \mathrm{E}_{\mathrm{Fe}}$ and $\mathrm{E}_{\mathrm{Total}}$ denotes the strength of a single active molecule on the Fe slab.

\subsection{Gravimetric Method using Response Surface \\ Methodology}

Using response surface methodology (RSM), the inhibition efficiency of SE extract was optimized by central composite design (CCD) tool of Design Expert Software (version 10). A total of 16 runs of experiments were conducted as listed in Table 7. The graphical analysis of inhibition efficiency of SE extract on carbon steel in $\mathrm{HCl}$ is presented in Fig. 7. Fig. 7A is plot of externally studentized residual versus runs number. The externally studentized residual is calculated by leaving the experimental runs in question out of the analysis and estimating the response from the remaining runs, Also it tests whether the experimental runs follows the model with coefficients estimated from the rest of the runs. As shown the normal plot of residuals versus internally studentized residuals is the residual divided by the estimated standard deviation of that residual. This measures the number of standard deviations separating the actual and
Table 7 Experimental and levels of CCD for $0.3 \mathrm{~g} \mathrm{~L}^{-1}$ and $1.5 \mathrm{~g} \mathrm{~L}^{-1} \mathrm{SE}$ on CS in $1 \mathrm{M} \mathrm{HCl}$.

\begin{tabular}{rccccc}
\hline Run & $\begin{array}{c}\mathrm{F}_{1}(\mathrm{IC}) \\
/ \mathrm{g} \mathrm{L}^{-1}\end{array}$ & $\begin{array}{c}\mathrm{F}_{2}(\mathrm{~T}) \\
/ \mathrm{K}\end{array}$ & $\mathrm{F}_{3}(\mathrm{AC})$ & $\begin{array}{c}\mathrm{F}_{4} \\
/ \mathrm{t}, \mathrm{h}\end{array}$ & $\begin{array}{c}\text { Response }{ }_{1} \mathrm{IE} \\
/ \%\end{array}$ \\
\hline 1 & 1.5 & 333 & 2 & 3 & 60.92 \\
2 & 1.5 & 333 & 1 & 6 & 68.96 \\
3 & 0.3 & 303 & 2 & 3 & 62.27 \\
4 & 1.5 & 303 & 1 & 6 & 86.88 \\
5 & 1.5 & 303 & 2 & 3 & 78.36 \\
6 & 1.5 & 333 & 1 & 6 & 68.96 \\
7 & 0.3 & 333 & 2 & 3 & 41.59 \\
8 & 0.3 & 333 & 2 & 6 & 61.52 \\
9 & 0.3 & 303 & 1 & 3 & 70.79 \\
10 & 1.5 & 303 & 1 & 6 & 86.88 \\
11 & 0.3 & 303 & 2 & 3 & 62.27 \\
12 & 0.3 & 333 & 1 & 6 & 52.87 \\
13 & 0.3 & 303 & 1 & 3 & 70.79 \\
14 & 0.3 & 333 & 1 & 6 & 71.72 \\
15 & 1.5 & 303 & 2 & 3 & 78.36 \\
16 & 0.3 & 333 & 2 & 3 & 41.59 \\
\hline & & & & & \\
\hline & & & & & \\
\hline
\end{tabular}

predicted values. The predicted versus actual plot; this is used to evaluate the signifance of the model's order. The plot reveals that the actual values are distributed relatively near to the straight line which indicates that the regression model is able to predict the inhibition efficiency. The characteristics of the 3-D surface plot suggest that there is a mutual interaction among the considered factors of the corrosion process and the efficacy of SE molecules. The nature of Fig. 7B indicate there is mutual correlation between temperature and inhibitor concentration because increase in temperature range reduces the activeness SE molecules for surface attachment on the corroding surface (break the 
heterocyclic bond of SE molecules) while increment in inhibitor concentration enhances the manifestation of a dense film layer in the physical state which promotes the level of surface coverage. Fig. 7C signifies that effect of inhibitor concentration and acid concentration on the inhibition efficiency is significant, from Table 7; it was observed that inhibition efficiency stabilizes by enhancing the concentration of SE active molecules thereby giving the optimum efficiency of $86.8 \%$ which conforms to the values of other corrosion techniques employed. Fig. 7D also signifies that acid concentration and temperature are the major corrosion agents, increasing both variables expedite the rate of metal dissolution this could be attributed to high temperature range, corrosiveness and $\mathrm{pH}$ of the studied environment.

\subsubsection{Statistical Modelling of the Corrosion Inhibition} Efficiency

The summary of P-values indicates that a 2FI factorial model fitted the ANOVA analysis and hence, the linear and 2FI models

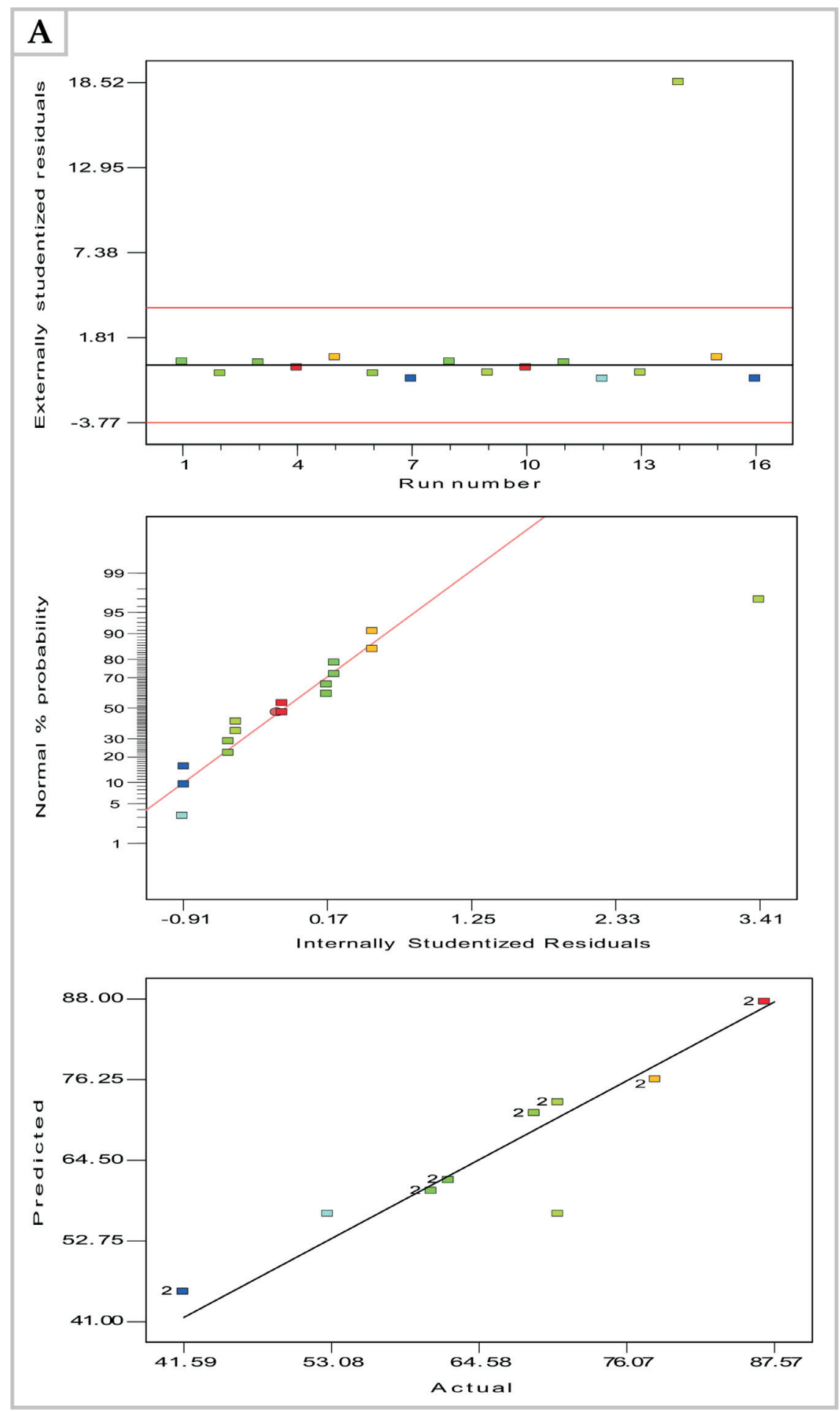

Figure 7A-D - (A) Response surface optimization plots for inhibition efficiency using Design Expert version 10: plot of externally studentized residual versus run number (top), normal plot of residuals versus internally studentized residuals (middle)and predicted versus actual plot for SE on CS in $1 \mathrm{M} \mathrm{HCl}$ (bottom). B-D: (B) Temperature versus inhibitor concentration, (C) inhibitor concentration versus acid concentration, (D) acid concentration versus temperature. (Continued on p. 172.) 
were suggested. The factorial model equations obtained for the inhibition efficiency of SE on corrosion of carbon steel in $\mathrm{HCl}$ is presented below

$$
\begin{aligned}
& \text { IE }(\%)=+239.03500+12.21667 X_{1}-0.54167 X_{2}- \\
& 5.66500 X_{3}+6.31 X_{1} X_{2}-6.56 X_{1} X_{3}-2.70------
\end{aligned}
$$

The experimental data generated for the inhibition process were statistically scrutinized for consistency and justification of the model. ANOVA table is given in Table 8; the F-value of 35.37 implies the model is significant which was validated by the $\mathrm{P}$-value being less than 0.05 . The P-values were used as a statistical parameter to scrutinize the significance of the regression coefficients, ${ }^{42}$ which in turn are essential to understand the phenomenon of the mutual interactions between the test variables. The larger the magnitude of F-test value and the smaller the magnitude of P-value the higher the significance of the corresponding coefficient. ${ }^{43}$ There is only a $0.01 \%$ chance that a 'Model F-Value' this large could occur due to noise. The noise may be assigned to flow rates of the chemical constituents present in the inhibitor. Values of ${ }^{\prime}$ Prob $>F^{\prime}$ less than 0.0500 indicate model terms are significant. In this case $X_{1}, X_{2}, X_{3}, X_{4}, X_{1} X_{2}$ $X_{1} X_{3}, X_{2} X_{3}$ are significant model terms. Values higher than 0.1000 reveal the model terms are not significant. The coefficient of regression $R^{2}$ was used to justify the fitness of the model equa-
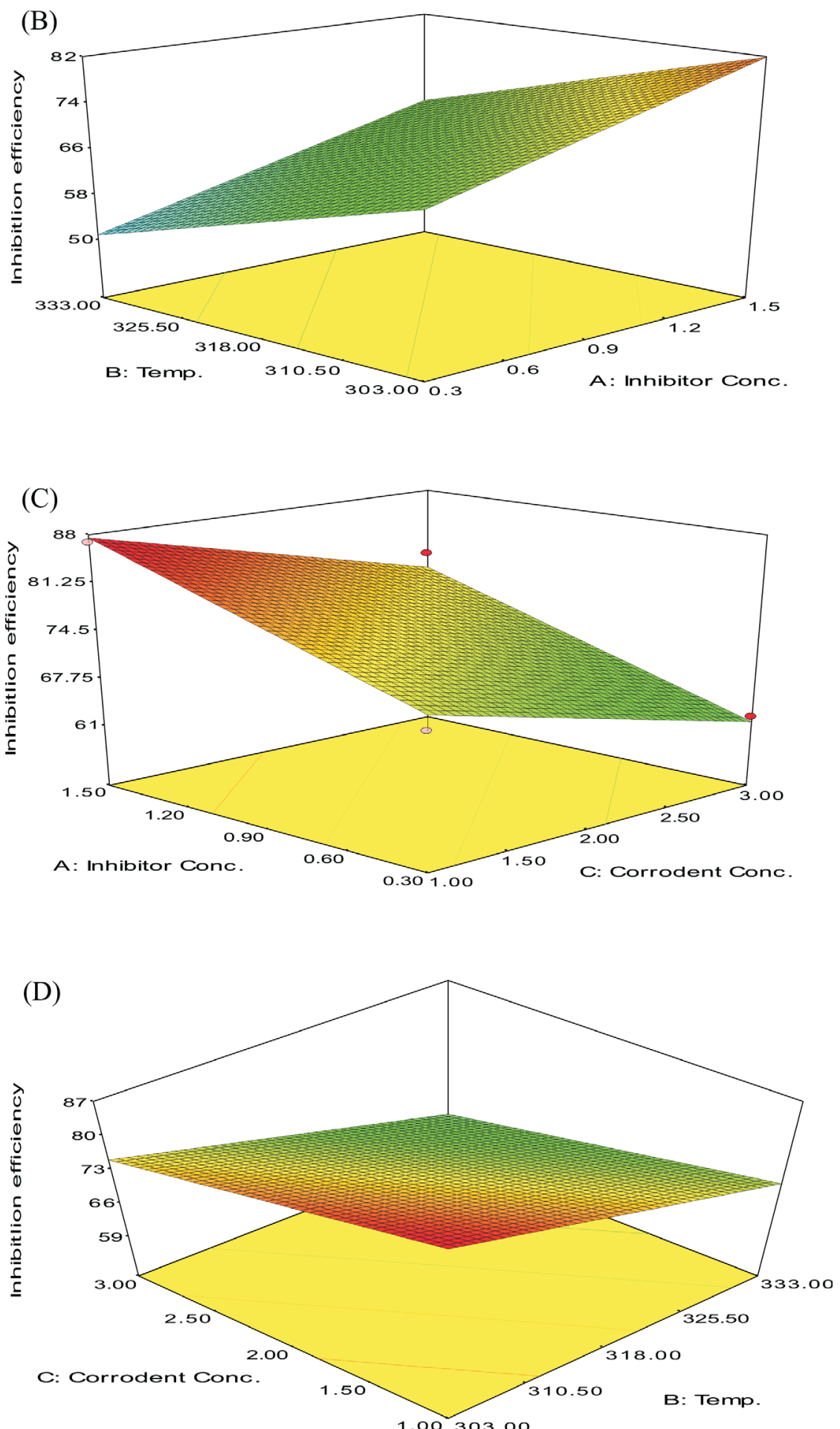

Figure 7 (continued) 
tion. The $\mathrm{R}^{2}$ has a high value of 0.8983 showing that $89.83 \%$ of the variability in the response can be explained by the model. This implies that the prediction of experimental data is quite satisfactory. ${ }^{44}$ The 'Pred R-Squared' of 0.8194 obtained is in conformity with the 'Adj R-Squared' of 0.8730. 'Adeq Precision' estimates the signal to noise ratio. A ratio above 4 is acceptable. The ratio of 17.655 demonstrates a good signal. Thus this model is therefore sufficient to navigate the design space. The final factorial model equations obtained for corrosion inhibition efficiency of SE on carbon steel in $\mathrm{HCl}$ after eliminating the insignificant model terms becomes as expressed in Equation (14).

$$
\begin{aligned}
& \text { IE }(\%)=+66.45+7.33 X_{1}-8.13 X_{2}-5.66 X_{3}+4.61 X_{1} X_{2}- \\
& 5.55 X_{1} X_{3}-3.970 X_{2} X_{3}-------
\end{aligned}
$$

\subsection{Surface Chemistry}

It is imperative to scrutinize the surface texture of the CS coupons. For good justification, scanning electron microscopy was employed to investigate the surface chemistry behind SE adsorption. The optical micrograph proves the mutual interaction of SE molecules and the surface of CS. The analysis was carried out in protected and unprotected medium. Fig. 8 shows the surface chemistry of CS immersed in $1 \mathrm{M} \mathrm{HCl}$ for $6 \mathrm{~h}$, it is obvious that the surface of the CS was severely damaged due to aggressive attack of $\mathrm{HCl}$ which resulted to the formation of dark flakes or corrosion products. ${ }^{45}$ Fig. 9 also shows the micrograph of CS in protected medium for $6 \mathrm{~h}$. It is evident the surface texture of the CS assume a perfect surface coating compared with Fig. $8 .^{46}$ The difference between the surface texture of Fig. 8 and Fig. 9 proves the existence of a protective film layer at the metal solution interface through attachment of SE molecules.

\section{Conclusion}

Carbon steel is highly susceptible to degradation in $1 \mathrm{M} \mathrm{HCl}$ and the inhibitor concentration studied acts effectively for mitigation of carbon steel corrosion under service conditions. The electrochemical investigation suggests that SE molecules is under mixed control (obstruct anodic and cathodic dissolution) and the molecular simulation approach predicted the adsorption areas, it also revealed that SE molecules assume a flat adsorption phenomenon on the CS surfaces. The pattern of SE

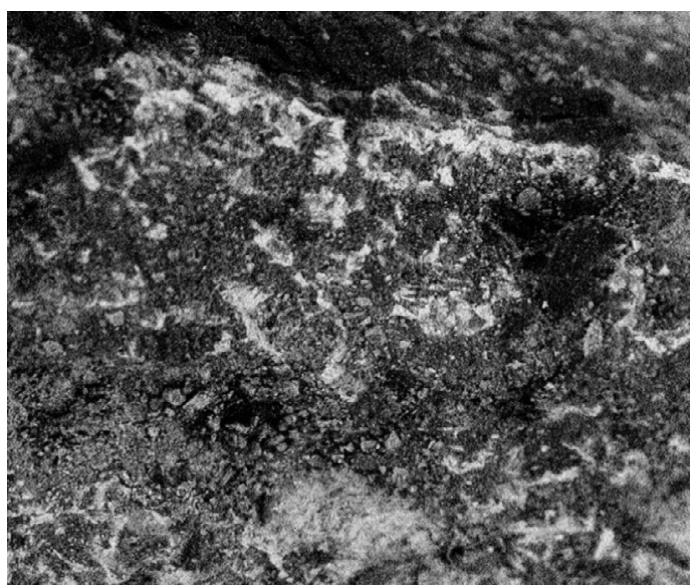

Figure 8 Carbon steel in $1 \mathrm{M} \mathrm{HCl}$ (blank).

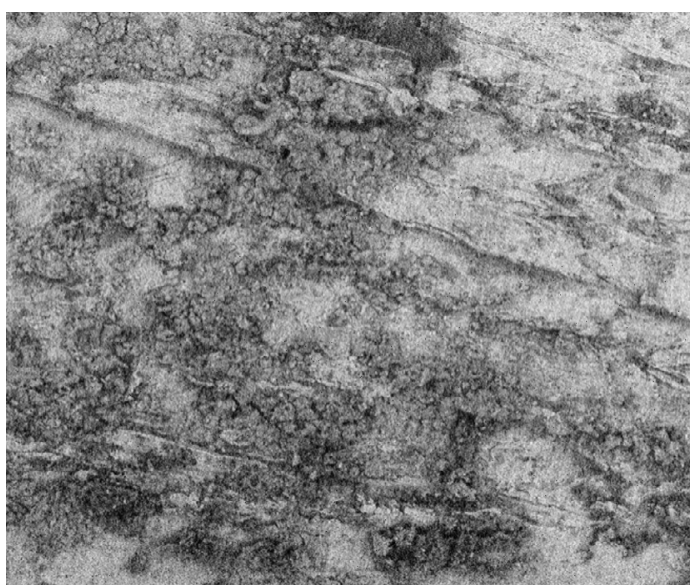

Figure 9 Carbon steel in $1 \mathrm{M} \mathrm{HCl} / 1.5 \mathrm{~g} \mathrm{~L}^{-1} \mathrm{SE}$.

adsorption process is well fitted in Langmuir isotherm. The statistical modelling is a unique approach for optimizing, modelling and predicting the efficacy of SE molecules as corrosion inhibitor. Hence, all the analytical techniques employed successfully provide excellent results which are in conformity with the literature.

\begin{tabular}{|c|c|c|c|c|c|c|}
\hline Source & $\mathrm{SSq}$ & $\mathrm{D}_{\mathrm{fr}}$ & MSq & $\mathrm{F}-\mathrm{V}$ & P-value & \\
\hline Model & 2429.388 & 3 & 809.796 & 35.371 & $<0.0001$ & Significant \\
\hline$X_{1}-I C$ & 859.6624 & 1 & 859.6624 & 37.5470 & $<0.0001$ & \\
\hline$X_{2}-T$ & 1056.25 & 1 & 1056.25 & 46.1333 & $<0.0001$ & \\
\hline$X_{3}-A C$ & 513.4756 & 1 & 513.4756 & 22.4268 & 0.0005 & \\
\hline$X_{4}-t$ & 311.606 & 1 & 311.606 & 19.831 & 0.0001 & \\
\hline$X_{1} X_{2}$ & 7.38976 & 1 & 7.38976 & 0.3833 & 0.02557 & \\
\hline $\mathrm{X}_{1} \mathrm{X}_{3}$ & 39.01 & 1 & 39.01 & 1.9643 & 0.03344 & \\
\hline$X_{2} X_{3}$ & 31.5844 & 1 & 31.5844 & 1.4373 & 0.02612 & \\
\hline Residual & 274.7472 & 12 & 22.8956 & & & \\
\hline Lack of fit & 114.184 & 4 & 28.546 & 1.422294 & 0.3105 & Not significant \\
\hline Pure error & 160.5632 & 8 & 20.0704 & & & \\
\hline Cor total & 2704.135 & 15 & & & & \\
\hline Mean & 66.45 & Adj. R-Squared & 0.87309 & & & \\
\hline C.V. $\%$ & 7.200805 & Pred R-Squared & 0.81943 & & & \\
\hline PRESS & 488.4395 & Adeq Precision & 17.65541 & & & \\
\hline
\end{tabular}

Table 8 ANOVA for IE\% of SE on corrosion of carbon steel in $1 \mathrm{M} \mathrm{HCl}$. 


\section{Acknowledgements}

The authors appreciate the Electrochemistry and Material Sci. Lab Unit, Department of Chemistry, Federal University of Technology Owerri, and Chemical Engineering Department, Ahmadu Bello University, Zaria, for the availability of modern analytical equipment use for the study.

\section{${ }^{5}$ ORCID iD}

\section{V.C. Anadebe: (iD orcid.org/0000-0002-7559-446X}

\section{References}

1 I.B. Obot and I.B. Onyeachu, Electrochemical frequency modulation (EFM) techniques: theory and recent practical applications in corrosion research, J. Mol. Liq., 2018, 249, 83-96.

2 P. Shetty, Hydrazide derivatives: an overview of their inhibition activity against acid corrosion of mild steel, S. Afr. J. Chem., 2018, 71, 46-50.

3 C.A. Loto, R.T. Loto and O.O. Joseph, Effect of benzamide on the corrosion inhibition of mild steel in sulphuric acid, S. Afr. J. Chem., 2017, 70, 38-43.

4 M.S. Al-Otaibi, A.M. Al-Mayouf, M. Khan, A.A. Mousa, S.A. Al-Mazroa, Corrosion inhibition action of some plants extracts on the corrosion of mild steel in acidic media, Arab. J. Chem., 2012, 1-7.

5 H. Ashassi-sorkhabi, N. Ghalebsaz-Jeddi, F. Hashemzadeh, H. Jahani, Corrosion inhibition of carbon steel in hydrochloric acid by some poly ethylene glycols, Electrochim. Acta, 2006, 51, 3848-3854.

6 N. Raghavendra and J. Ishwara Bhat, Anti-corrosion properties of areca palm leaf extract on aluminum in $0.5 \mathrm{M} \mathrm{HCl}$ environment, S. Afr. J. Chem., 2018, 71, 30-38.

7 A. Bader, U. Shaheen, M.A.S. Aborehab, Y. El Ouadi, A. Bouyanzer, B. Hammouti and T. Ben Hadda, Inhibitory effect of Acacia hamulosa methanol extract on the corrosion of mild steel in $1 \mathrm{M} \mathrm{HCl}$ acid, Bull. Chem. Soc. Ethiop., 2018, 32(2), 323-335.

8 Y. Qiang, Z. Shengtao, T. Bochuan, C. Shijin, Evaluation of ginkgo leaf extract as an eco-friendly corrosion inhibitor of X70 steel in $\mathrm{HCl}$ solution, Corros. Sci., 2018, 133, 6-16.

9 T.L. Roland, Surface coverage and corrosion inhibition effect of Rosmarinus officinalis and zinc oxide on the electrochemical performance of low carbon steel in dilute acid solutions, Results Phys., 2018, 8, 172-179.

10 V.C. Anadebe, O.D. Onukwuli, M. Omotioma and N.A. Okafor, Optimization and electrochemical study on the control of mild steel corrosion in hydrochloric acid solution with bitter kola leaf extract as inhibitor, S. Afr. J. Chem., 2018, 71, 51-61.

11 R. Ragul, S. Kathiravan, A. Murugesh and J. Raichandran, Anti-corrosion performance of Mitracarpus hirtus extract on mild steel in $1 \mathrm{M}$ $\mathrm{HCl}$, J. Bio. Tribo. Corros., 2018, 4, 63.

12 N. Bhardwaj, D. Prasad and R. Haldhar, Study of the Aegle marmelos as a green corrosion inhibitor for mild steel in acidic medium: experimental and theoretical approach, J. Bio. Tribo. Corros., 2018, 4, 61.

13 O.M. Ighodaro, O.A. Akinloye, R.N. Ubaja and S.O. Omotainse, Sapium ellipticum (Hochst) Pax ethanol leaf extract modulates glucokinase and glucose-6-phosophate activities in streptozotocin induced rats, Asian Pacific J. Trop. Biomed., 2017, 7(6), 544-548.

14 A.A. Khadom, N.A. Ahmed and A.A. Nagham, Xanthium strumarium leaves extracts as a friendly corrosion inhibitor of low carbon steel in HCl: kinetics and mathematical studies, S. Afr. J. Chem. Eng., 2017, 25, 13-21.

15 A.A Khadom, A.F. Hassan and B.M. Abod, Evaluation of environmentally friendly inhibitor for galvanic corrosion of steel-copper couple in petroleum waste water, Process Safety. Env. Protection, 2015, 98, 93-101.

16 M. Omotioma and O.D. Onukwuli, Modeling the corrosion inhibition of mild steel steel in $\mathrm{HCl}$ medium with the inhibitor of pawpaw leaves extract, Port. Electrochim. Acta, 2016, 34, 287-294.

17 N. Nagm, N.G. Kandile, E.A. Badr and M.A. Mohammed, Gravimetric and electrochemical evolution of environmentally friendly nonionic corrosion inhibitors for carbon steel in $1 \mathrm{M} \mathrm{HCl}$, Corros. Sci., 2012, 65, 94-103.

18 M.A. Chidiebere, E.E. Oguzie, L. Liu, L. Ying and F. Wang, Adsorption and corrosion inhibiting effect of riboflavin on Q235 mild steel corrosion in acidic environments, Mater. Chem. Phys., 2015, 156, 95-104.

19 V.S. Rav and L.K. Singhal, Corrosion behavior and passive film chem- istry of 216L stainless steel in sulphuric acid, J. Mater. Sci., 2009, 44(9), 2327-2333.

20 G. Ji, S. Anjum, S. Sundaram and R. Prakash, Musa paradisica peel extract as green corrosion inhibitor for mild steel in $\mathrm{HCl}$ solution, Corros. Sci., 2015, 90, 107-117.

21 D. Daoud, T. Daoud, H. Hamani, S. Chafaa and M. Al-Noami, Corrosion inhibition of mild steel by two new S-heterocyclic compounds in $1 \mathrm{M} \mathrm{HCl}$ : experimental and computational study, Corros. Sci., 2015, 94, 21-37.

22 K. Yadav, A. Gupta, S. Noyel and R. Manivannan, Murraya kognigii as green corrosion inhibitor for mild steel in nitric acid medium, Ind. J. Chem. Tech., 2018, 25, 94-100.

23 Y. Qiang, L. Guo, S. Zhang, W. Li, S. Yu and J. Tan, Synthesis effect of tartaric acid with 2,6-diaminopyridine on the corrosion inhibition of mild steel in 0.5M HCl, Sci. Rep., 2016, 6, 33305 .

24 Z. Tao, W. He, S. Wang and G. Zhou, Electrochemical study of cyproconazole as a novel corrosion inhibitor for copper in acidic solution, Ind. Eng. Chem. Res., 2013, 52, 17891-17899.

25 F.S. De souza and A. Spinelli., Caffeic acid as a green corrosion inhibitor for mild steel, Corros. Sci., 2009, 51, 642-649.

26 L.G. Da trindade and R.S. Goncalves, Evidence of caffeine adsorption on low carbon steel surface in ethanol, Corros. Sci., 2009, 51, 1543-1578.

27 J. Wysoka, S. Krakowiak and J. Ryl, Evaluation of citric acid corrosion inhibition efficiency and passivation kinetics for aluminum alloys in alkaline media by means of dynamics impedance monitoring, Electrochim. Acta, 2017, 258, 1463-1475.

28 A. Singh, K.R. Ansari, J. Haque, P. Dohare, H. Lgaz, R. Salghi and M.A. Quraishi, Effect of electron donating functional groups on corrosion inhibition of mild steel in $\mathrm{HCl}$ : experimental and quantum chemical study, J. Taiwanese Inst. Chem. Eng., 2018, 82, 233-251.

29 B. Tan, S. Zhang, Y. Qiang, L. Guo, L. Feng, C. Liao, Y. Xu and S. Chen, A combined experimental and theoretical study of the inhibition effect of three disulfide-based flavoring agents for copper corrosion in $0.5 \mathrm{M}$ sulfuric acid, J. Colloid Interface Sci., 2018, 526, 268-280.

30 V.C. Anadebe, O.D. Onukwuli, M. Omotioma and N.A. Okafor, Experiment, theoretical modeling and optimization of inhibition efficiency of pigeon pea leaf extract as anti-corrosion agent of mild steel in acid environment, Mater. Chem. Phys., 2019, 233, 120-132.

31 Z. Bensouda, M. Driouch, R.A. Belakhmima, M. Sfaira, M.E. Touhami and A. Farah, Thymus sahraouian essential oil as corrosion inhibitor for mild steel in a molar hydrochloric acid solution, Portugaliae Electrochim. Acta, 2018, 36(5), 339-364.

32 A.S. Fouda, S.M. Rashwan, M.M.K. Darwish and N.M. Arman, Corrosion inhibition of $\mathrm{Zn}$ in a $0.5 \mathrm{M} \mathrm{HCl}$ solution by Ailanthus altissima extract, Portugaliae Electrochim. Acta, 2018, 36(5), 309-323.

33 F. El-Hajjaji, E.B. Mohammed, M. Drissi, M. Fahim, R.Salim, B. Hammouti, M. Taleb and A. Nahle, Electrochemical, quantum calculations and monte carlo simulations studies of N1, N2 bis (1- phenylethylidene) ethane-1,2-diamine as a corrosion inhibitor for carbon steel in a $1.0 \mathrm{M}$ hydrochloric acid solution, Portugaliae Electrochim. Acta, 2018, 37(1), 23-42.

34 A.S. Fouda, E.H. Megahed, N. Fouda and N.M. Elbahrawt., Corrosion inhibition of carbon steel in 1.M hydrochloric acid solution by aqueous extract of Thevetia peruviana, J. Bio. Tribo. Corros., 2016, 2, $1-16$.

35 H. Lgaz, R. Salghi and S. Jodeh, Effect of clozapine on inhibition of mild steel corrosion in $\mathrm{M} \mathrm{HCl}$ medium, J. Mol. Liq., 2017, 225, 271-280.

36 N.O. Eddy and I.B. Ita, Experimental and theoretical studies on the inhibition potentials of some derivatives of cyclopenta-1,3-diene, Int . J. Quantum Chem., 2011, 111, 3456-3473.

37 R.N. Singh, A. Kumar and R.K. Tiwari, A combined experimental and theoretical (DFT and AIM) studies on synthesis, molecular structure, spectroscopic properties and multiple interactions analysis in a novel ethyl-4-[2-(thiocarbamoyl) hydrazinylidene-3,5-dimethyl-1H-pyrrole-2-carboxylate and its dimer, Spectrochim. Acta A. Mol. Biomol. Spectrosc., 2013, 112, 182-190.

38 H. Jafari, I. Danaee and H. Eskandari, Combined computational and experimental study on the adsorption and inhibition effects of N2 $\mathrm{O} 2$ Schiff base on the corrosion of API 5L grade B steel in $1 \mathrm{M} \mathrm{HCl}$, J. Mater. Sci. Tech., 2014, 30, 239-252.

39 N.O. Eddy and I.B. Ita, Theoretical and experimental studies on the inhibition potentials of aromatic oxaldehydes for the corrosion of mild steel in 0.1 M HCl, J. Mol. Model., 2011, 17, 633-647.

40 N.A. Wazzan, DFT calculation of thiosemicarbazide, arylisothio- 
cynates and 1-aryl-2,5-dithiohydrazodicaronamides as corrosion inhibitors of copper in aqueous chloride solution, J. Ind. Eng. Chem. 2015, 26, 291-308.

41 Y. Sheng, Hiu Yan, L. Zhang, M. Shan, P. Chen, A. Ding and S.F. Yau$\mathrm{Li}$, A review on the phytochemistry, pharmacology and pharmacokinetics of amentoflavone, a naturally occurring bioflavonoid, Molecules, 2017, 22, 299,

DOI: $10.3390 /$ molecules22020299

42 J.O. Odejobi and A.A. Olatunde, Modeling and optimization of the inhibition efficiency of Euphorbia heterophylla extracts based corrosion inhibitor of mild steel corrosion in $\mathrm{HCl}$ medium using response surface methodology, J. Chem. Tech. Metallurgy, 2019, 54, 217-232.

43 S.B. Imadi, V.R. Bandaru, S.R. Somalanka and H.R. Garapati, Optimization of medium constituents for the production of citric acid from by-products using Doehlert experimental design, Enzym. Microb. Technol., 2007, 40, 1367-1372.

44 P. Sharma, L. Singh and N. Dilbaghi, Optimization of green variables for decolorization of disperse yellow 211 by Bascillus subtiles using Box-Behnken design, J. Hazard. Mater., 2009, 164, 1024-1029.

45 S. Chaithra, A. Gupta, R. Manivannan and S. N. Victoria, Studies on corrosion inhibitory action of Ocimum sanctum (Tulsi) leaves extract in mild steel corrosion induced by Desulfovibrio desulfuricans, Indian J. Chem. Tech., 2018, 25, 441-450.

46 C.A. Loto, O.S. Isaac Fayomi, R.T. Loto and A.P.I. Popoola, Potentiodynamics polarization and gravimetric evaluation of corrosion of copper in $2 \mathrm{M} \mathrm{H}_{2} \mathrm{SO}_{4}$ in absence and presence of ammonium dichromate as an inhibitor, J. Chem. Tech. Metallurgy, 2019, 54, 209-216. 